\title{
Chlorophyll fluorescence emission of tomato plants as a response to pulsed light based LEDs
}

\author{
Ernesto Olvera-González • Daniel Alaniz-Lumbreras • Rumen Ivanov-Tsonchev • \\ Jesús Villa-Hernández • Ismael de la Rosa-Vargas • Irineo López-Cruz • \\ Héctor Silos-Espino • Alfredo Lara-Herrera
}

Received: 14 February 2012/ Accepted: 15 September 2012/Published online: 5 February 2013

(c) The Author(s) 2013. This article is published with open access at Springerlink.com

\begin{abstract}
The effects of pulsed light based-LEDs at eleven frequencies $(0.1,1,10,50,100,500 \mathrm{~Hz}, 1,5,10,50$ and $100 \mathrm{kHz}$ ) programmed at $50 \%$ duty cycle were analyzed, obtaining important parameters of the fluorescence emission of chlorophyll such as: maximum fluorescence $\left(\mathrm{Fm}^{\prime}\right)$, minimum fluorescence, the fluorescence emission in steady state, maximum efficiency of PSII $\left(\mathrm{Fv}^{\prime} / \mathrm{Fm}^{\prime}\right)$, the fraction of PSII centers that are open, photochemical quenching, nonphotochemical quenching (NPQ), quantum efficiency of photosystem II (ФPSII), electron transport rate (ETR) and quantum yield of $\mathrm{CO}_{2}$ assimilation $\left(\phi \mathrm{CO}_{2}\right)$. For the study and validation of the results obtained in the
\end{abstract}

E. Olvera-González · D. Alaniz-Lumbreras ( $₫)$.

J. Villa-Hernández · I. de la Rosa-Vargas

Facultad de Ingeniería Eléctrica, Doctorado en Ciencias de la Ingeniería, Universidad Autónoma de Zacatecas, Avenida Ramón López Velarde 801, C.P. 98000 Zacatecas, Mexico e-mail: dalaniz@uaz.edu.mx

R. Ivanov-Tsonchev

Facultad de Física, Universidad Autónoma de Zacatecas, Calz. Solidaridad Esquina Paseo de la Bufa s/n, C.P. 98060 Zacatecas, Zac, Mexico

I. López-Cruz

Posgrado en Ingeniería Agrícola y Uso Integral del Agua, Universidad Autónoma Chapingo, Km. 38.5 carretera MéxicoTexcoco, C.P. 36230 Chapingo, Edo. de México, Mexico

H. Silos-Espino

Laboratorio de Análisis Químicos y Bioquímicos de Plantas, Instituto Tecnológico El Llano, Aguascalientes. km 18 carr. Aguascalientes-San Luis Potosí, C.P. 20330 El Llano, Ags, Mexico

\section{A. Lara-Herrera}

Unidad Académica de Agronomía, Universidad Autónoma de Zacatecas, Jardín Juárez 147, C.P. 98000 Zacatecas, Mexico experiments, the analysis of variance (ANOVA) was applied Ofor each parameter with confidence intervals of $95 \%$. The results show that the frequencies of pulsed light had positive and negative effects on the fluorescence parameters with respect to the control treatment (continuous light). The frequencies that generated the best performance of $\mathrm{Fv}^{\prime} / \mathrm{Fm}^{\prime}, \mathrm{NPQ}$, ФPSII, ETR, $\phi \mathrm{CO}_{2}$ in tomato plants were $0.1,1,100 \mathrm{~Hz}$, and $1 \mathrm{kHz}$. The increase obtained in these parameters can represent an optimal growth and productivity conditions for optimal energy consumption.

Keywords Chlorophyll fluorescence $\cdot$ Pulsed light . LEDs · Growth plants

\section{Introduction}

Light is a source of information affecting germination, phototropism, flowering time, development of chloroplasts movements in leaves and stomata with which plants control photosynthesis (Goto 2003; Spalding and Folta 2005). Light also provides energy for plants to synthesize organic compounds. There are several factors related to light that are involved in growth and development of plants like quality and quantity of the light, and photoperiod (Goto 2003). These factors can be easily manipulated in growth chambers, growth rooms and partially controlled in greenhouses.

There exist a wide variety of artificial light sources for plant growth: metal halide (MH), fluorescent lamps, high pressure sodium lamps and solid state lighting (LEDs). To evaluate the effects of light on the plant growth (quality and quantity), different light sources were applied during the growth of lettuce, tomato, spinach, and cucumber (Bula 
et al. 1991; Barta et al. 1992; Hoenecke et al. 1992; Okamoto et al. 1996; Yorio et al. 2001; Dougher and Bugbee 2001). These different sources of artificial light have advantages and disadvantages related to cost, quality of light, the percentage of photosynthetic photon emitted, energy efficiency, infrared emissions and ultraviolet emissions.

Recently, the use of light emitting diodes (LEDs) as sources of artificial radiation for plant growth has increased and has been used to study the photosynthesis and the photomorphogenic responses (Bula et al. 1991; Tennessen et al. 1994; Goins et al. 1997; Wongnok et al. 2008). LEDs compared with other sources of artificial radiation have significant advantages because of they can be designed to emit specific wavelengths required for optimal plant growth (Hogewoning et al. 2007). Some systems have been developed based on power LEDs for plant growth, obtaining better results than traditional lighting systems (Folta et al. 2005; Hu et al. 2007; Yanagi and Okamoto 1997).

Another advantage of artificial lighting based on LEDs is the possibility to emit pulsed light with different wavelengths which might be beneficial to plant development (Tamulaitis et al. 2005). Pulsed light was applied at different frequencies and duty cycles for the study of phototropism induced in seedlings of Arabidopsis thaliana (Steinitz and Poff 1986). They showed that continuous light can be replaced with pulsed light. Tennessen et al. (1995) analyzed the photosynthetic response of tomato plants applying short pulses (2 ms of light and $198 \mathrm{~ms}$ of darkness) and continuous lighting. They found continuous light presented better a photosynthetic rate than the pulsed light used. Yoneda and Mori (2004) developed an artificial lighting system with pulsed light to measure the photosynthetic activity and fresh weight in lettuce plants and obtained better results by applying light pulses of $100 \mathrm{~ms}$ $(10 \mathrm{kHz})$ with a duty cycle of $50 \%$. However, these studies do not consider higher frequency ranges. If we consider more frequencies of pulsed light, we can get a better analysis about of the effect of pulsed light on plant growth.

Emission measurements of chlorophyll fluorescence has been used as a tool to understand the behavior of plant growth (Mishra et al. 2011; Joiner et al. 2011; Wang et al. 2009; Xu et al. 2008; González Moreno et al. 2008). There exists very limited information on the effect of pulsed light using chlorophyll fluorescence emissions as a variable in the study of tomato plants. Therefore, the aim of this study was to analyze the behavior of the basic parameters of the chlorophyll fluorescence emission in tomato plants ( $\mathrm{Lyc}$ opersicon esculentum) under the effect of pulsed light with eleven different frequencies from $0.1 \mathrm{~Hz}$ to $100 \mathrm{kHz}$ at a duty cycle of $50 \%$ compared to continuous light determining the following parameters: quantum efficiency of photosystem II (ФPSII), electron transport rate (ETR) and quantum yield of $\mathrm{CO}_{2}$ assimilation $\left(\phi \mathrm{CO}_{2}\right)$. The experimental results showed that the fluorescence emission depended significantly on the frequency of pulsed light, discovering frequencies that generated greater benefit for plant growth with respect to the light traditionally applied (continuous light).

\section{Materials}

Figure 1 shows a scheme of the experimental setup used to determine the effects of different frequencies of pulsed light $(0.1,1,10,50,100,500 \mathrm{~Hz}, 1,5,10,50$ and $100 \mathrm{kHz})$ at $50 \%$ duty cycle. Continuous light was applied as a control treatment. Figure 2 shows the emission spectrum of the three commercial LEDs lamps for plant growth (EarthLED, Advanced Lumonics) used. A signal generator and a modulator output of 150 watts were used in the experiment. Tomato plants (L. esculentum) were grown for 60 days in a greenhouse measuring $4 \mathrm{~m}$ wide, $6 \mathrm{~m}$ long and $3 \mathrm{~m}$ high, with average day temperature of $30^{\circ} \mathrm{C}$ and an average night temperature of $18{ }^{\circ} \mathrm{C}$. All light treatments were applied inside a growth chamber measuring $3 \mathrm{~m}$ wide, $4 \mathrm{~m}$ long and $2.5 \mathrm{~m}$ high. The parameters inside the chamber were the following: temperature $25 \pm 1{ }^{\circ} \mathrm{C}$, relative humidity $55 \pm 2 \%, \mathrm{CO}_{2}$ concentration $400 \pm 10 \mathrm{ppm}$, and light intensity $750 \mathrm{~mol} \mathrm{~m}^{-1} \mathrm{~s}^{-1} \pm 15 \mathrm{mmol}$.

\section{Methods}

Five plants with the same age and same leaf size were used in the experiment. Five replicate were made for each leaf and the experiment was repeated three times. For each light treatment, the following basic parameters of the fluorescence emission were evaluated: maximum fluorescence $\left(\mathrm{Fm}^{\prime}\right)$, minimum fluorescence $\left(\mathrm{Fo}^{\prime}\right)$ and the fluorescence emission in steady state (Fs). These parameters were measured with Hansatech Instruments' fluorescence monitoring system (FSM 1). From the basic parameters $\left(\mathrm{Fo}^{\prime}, \mathrm{Fm}^{\prime}\right.$ and $\left.\mathrm{Fs}\right)$ we calculated: maximum efficiency of PSII $\left(\mathrm{Fv}^{\prime} / \mathrm{Fm}^{\prime}\right)$, the fraction of PSII centers that are open $\left(\mathrm{qL}=\left(\mathrm{Fq}^{\prime} / \mathrm{Fv}^{\prime}\right)\left(\mathrm{Fo}^{\prime} /\right.\right.$ $\mathrm{Fs})$, Photochemical quenching $\left(\mathrm{qP}=\mathrm{Fq}^{\prime} / \mathrm{Fv}^{\prime}\right)$, and nonphotochemical quenching $\left(\mathrm{NPQ}=\left(\mathrm{Fm} / \mathrm{Fm}^{\prime}\right)-1\right)$, according to Baker (2008).

The parameter ФPSII (Genty et al. 1989) indicates the proportion of light absorbed by chlorophyll associated with Photosystem II and is used for the plant photochemistry (Maxwell and Johnson 2000). Furthermore, this parameter is directly related to ETR and $\phi \mathrm{CO}_{2}$ according to the Eqs. (1) and (2) (Maxwell and Johnson 2000; Baker 2008): 
Fig. 1 General schematic representation of how the experiment was setup in order to determine the effects of different pulsed light frequencies in tomato plants

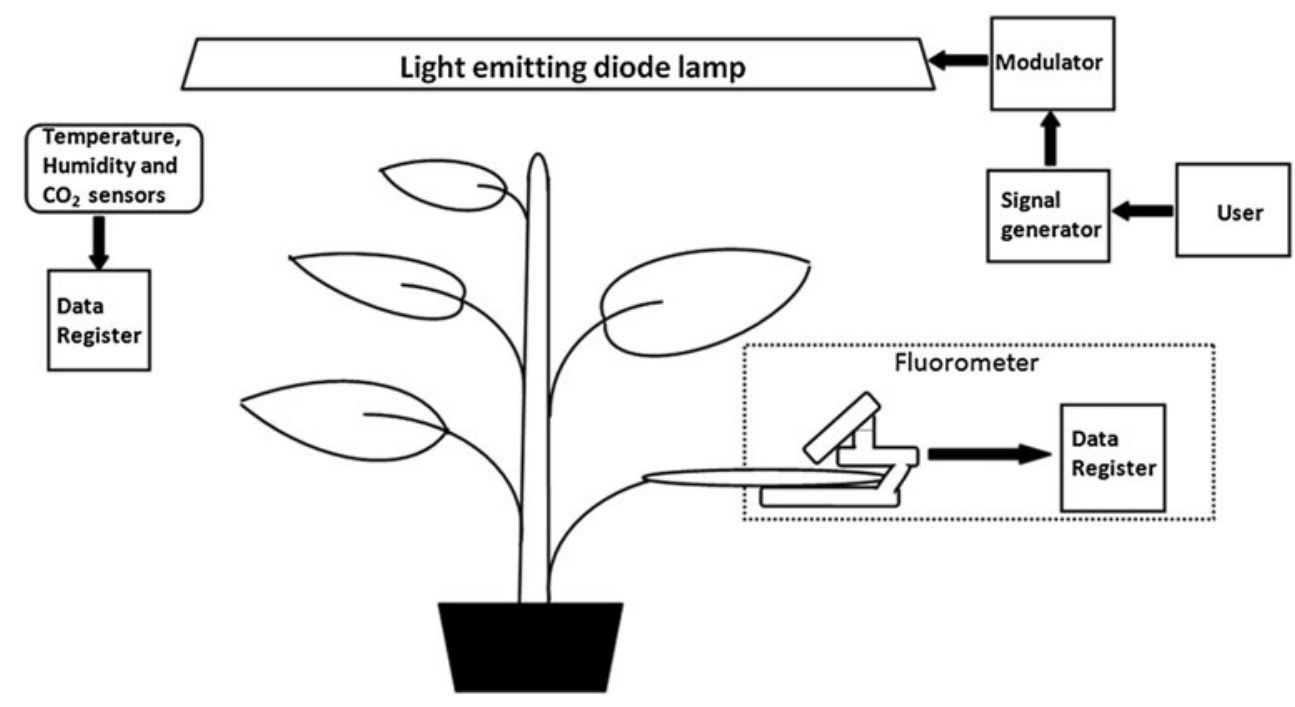

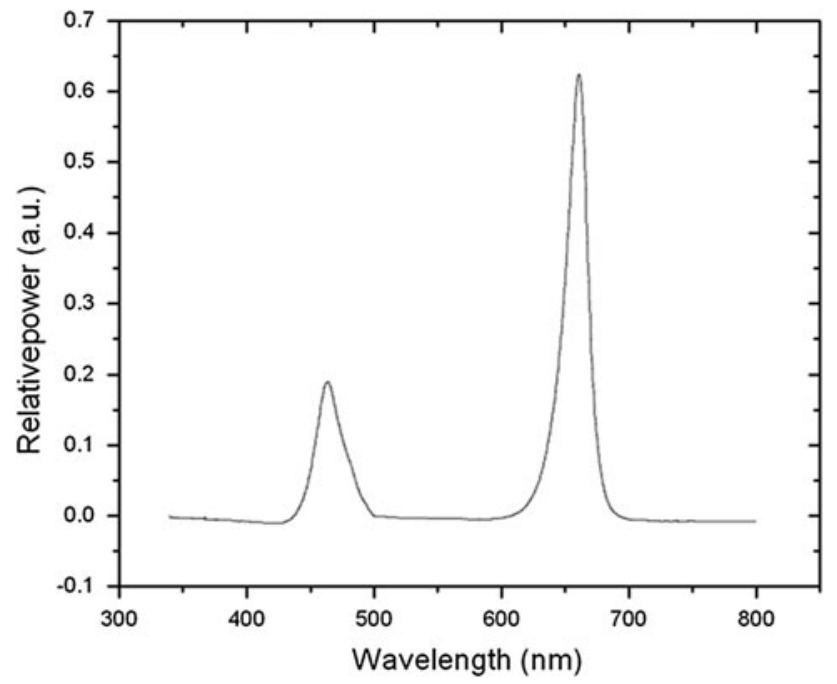

Fig. 2 Emission spectrum of the LEDs lamps (EarthLED) used in the experiment. The wavelength of blue was $460 \pm 25 \mathrm{~nm}$ and the wavelength of red was $660 \pm 30 \mathrm{~nm}$

$$
\begin{aligned}
& \mathrm{ETR}=\Phi \text { PSII } \times \text { PAR } \times 0.84 \times \text { fraction PSII } \\
& \phi \mathrm{CO}_{2}=\Phi \text { PSII } \times \text { fraction PSII } \times(1 / 4)
\end{aligned}
$$

where $\mathrm{ETR}=$ electron transport rate, $\Phi \mathrm{PSII}=$ quantum efficiency of photosystem II, PAR = photosynthetically active radiation $\left(\mu \mathrm{mol} \mathrm{m}{ }^{-1} \mathrm{~s}^{-1}\right)$, Fraction PSII $=$ light captured by Photosystem II (normally 0.5), $\phi \mathrm{CO}_{2}=$ quantum yield of $\mathrm{CO}_{2}$ assimilation.

\section{Statistical analysis}

A normality test to the data was carried out using both the Jarque-Bera and Lilliefors goodness-of-fit tests. Since several treatments did not overcome these tests, a nonparametric one-way analysis of variance (ANOVA) was
Table 1 Kruskal-Wallis ANOVA to validate the measured data and the ratio $\left(R^{2}\right)$ sum of squares among treatments, total sum of squares with $95 \%(\alpha=0.05)$ of confidence intervals

\begin{tabular}{lll}
\hline Parameter of chlorophyll fluorescence & Value $p$ & $R^{2}$ \\
\hline $\mathrm{Fo}^{\prime}$ & 0.064 & 0.54 \\
$\mathrm{Fm}^{\prime}$ & 0.062 & 0.54 \\
$\mathrm{Fs}$ & 0.005 & 0.76 \\
$\mathrm{qL}$ & 0.012 & 0.69 \\
$\mathrm{Fv} / \mathrm{Fm}^{\prime}$ & 0.062 & 0.54 \\
$\mathrm{qP}$ & 0.036 & 0.59 \\
$\mathrm{NPQ}$ & 0.062 & 0.54 \\
$\phi P S I I$ & 0.002 & 0.86 \\
$\mathrm{ETR}$ & 0.002 & 0.86 \\
$\phi \mathrm{CO}_{2}$ & 0.002 & 0.86 \\
\hline
\end{tabular}

The chlorophyll fluorescence parameters are significantly sensitive to the pulsed light frequencies, if $p$ value associated with each parameter is less than 0.05

performed (Table 1). Next, the Dunn's test was done to determine significant differences among treatments (Table 2). Also the ratio $\left(R^{2}\right)$ sum of squares among treatments, total sum of squares was calculated. The statistical analysis was performed using the computer software (Minitab 2003). The effects of pulsed light on the basic parameters of the chlorophyll fluorescence emission $\mathrm{Fm}^{\prime}, \mathrm{Fo}^{\prime}, \mathrm{Fs}, \mathrm{Fv}^{\prime} / \mathrm{Fm}^{\prime}$, qL, qP, NPQ, ФPSII, and calculated parameters the ETR and $\phi \mathrm{CO}_{2}$ were analyzed.

\section{Results and discussion}

Measurements of chlorophyll fluorescence emission in tomato plants during illumination with pulsed light at different frequencies revealed particular behaviors (Fig. 3). 
Table 2 Analysis of multiple comparisons based on Dunn's test

\begin{tabular}{ll}
\hline $\begin{array}{l}\text { Parameter of chlorophyll } \\
\text { fluorescence }\end{array}$ & $\begin{array}{l}\text { Significant differences } \\
\text { between }\end{array}$ \\
\hline Fs & $50 \mathrm{~Hz}$ and $100 \mathrm{kHz}$ \\
qL & - \\
qP & - \\
$\phi$ PSII & $0.1 \mathrm{~Hz}$ and $50 \mathrm{kHz}$ \\
& $1 \mathrm{~Hz}$ and $50 \mathrm{kHz}$ \\
& $1 \mathrm{~Hz}$ and $100 \mathrm{kHz}$ \\
ETR & $0.1 \mathrm{~Hz}$ and $50 \mathrm{kHz}$ \\
& $1 \mathrm{~Hz}$ and $50 \mathrm{kHz}$ \\
& $1 \mathrm{~Hz}$ and $100 \mathrm{kHz}$ \\
$\phi \mathrm{CO}_{2}$ & $1 \mathrm{~Hz}$ and $50 \mathrm{kHz}$ \\
& $1 \mathrm{~Hz}$ and $100 \mathrm{kHz}$
\end{tabular}

“_" no significant differences between treatments

The $\mathrm{Fm}^{\prime}\left(R^{2}=0.54, p=0.062\right)$ was maintained in the $500-600$ range for frequencies from $0.1 \mathrm{~Hz}$ to $10 \mathrm{kHz}$ including continuous light (control), however, for frequencies of 50 and $100 \mathrm{kHz}$ fluorescence it increased sharply to 800 and 1,100 respectively (Fig. 3a). Figure 3c shows that the $\mathrm{Fo}^{\prime}\left(R^{2}=0.54, p=0.064\right)$ varied between 42 and 52 at frequencies below $50 \mathrm{kHz}$, while at a frequency of $100 \mathrm{kHz}$ the value of Fo' was increased to 170 . The $\mathrm{Fm}^{\prime}$ and $\mathrm{Fo}^{\prime}$ parameters are determined both by the physicochemical properties of PSII and the optical properties of the leaf. The optical properties of the leaf could be modified depending on the amount of water present in the leaves (Baker 2008). The increase or decrease in Fm' and $\mathrm{Fo}^{\prime}$ directly affects the behavior of NPQ, $\mathrm{qP}, \mathrm{qL}$ and $\Phi \mathrm{PSII}$ parameters. According to the $p$ value of $\mathrm{Fm}^{\prime}$ and $\mathrm{Fo}^{\prime}$ of 0.54 , there is no significant relationship between the pulsed light and these parameters. Figure $3 \mathrm{~b}$ shows that the Fs $\left(R^{2}=0.76, p=0.005\right)$ behaved differently for each frequency, i.e., the values could be divided into lowest, middle, high and highest depending on the different frequency. The highest values corresponded to the frequencies 50 and $100 \mathrm{kHz}$ with values of 605 and 710, respectively. High values were observed at $10 \mathrm{kHz}, 500,10 \mathrm{~Hz}$ and control treatment (continuous light) with values at 303 , 300, 320 and 331, respectively. The middle values of Fs corresponded to the frequencies $5 \mathrm{kHz}, 100,50$ and $1 \mathrm{~Hz}$ with values at $268,252,257$ and 248 , respectively. The lowest values of Fs corresponded to the frequencies of $1 \mathrm{kHz}$ and $0.1 \mathrm{~Hz}$ with values of 168 and 191, respectively. The $p$ value of Fs parameter was 0.005 which is below 0.05 (95\%), indicating that there is a significant relationship between pulsed light and Fs. The optimal values for Fs parameter were obtained at frequencies of $0.1,1,100 \mathrm{~Hz}$ and $1 \mathrm{kHz}$.
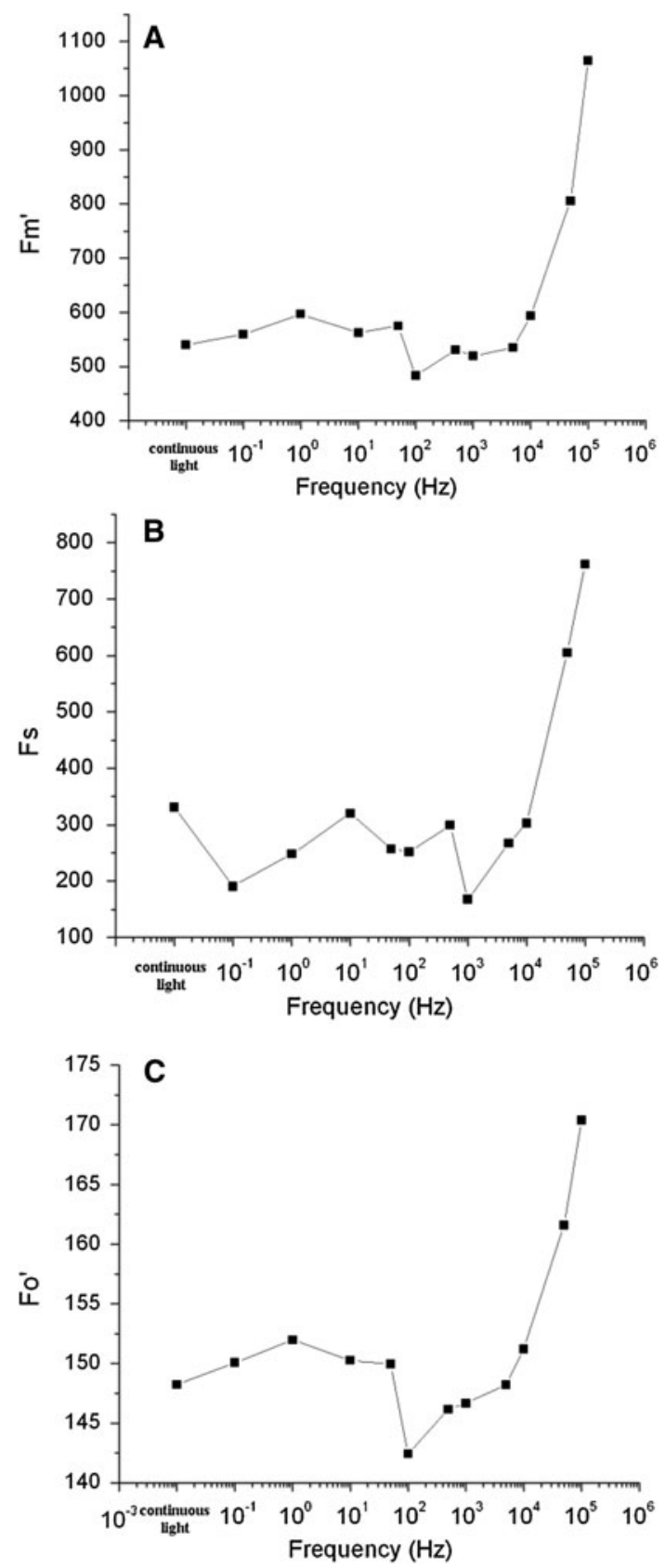

Fig. 3 Chlorophyll fluorescence emission yields as a function of frequency from $0.1 \mathrm{~Hz}$ down to $100 \mathrm{kHz}$ for tomato plants. Maximum fluorescence from light-adapted leaf $\left(\mathrm{Fm}^{\prime}\right)(\mathbf{a})$, steady state fluorescence (Fs) (b) and minimal fluorescence from lightadapted leaf $\left(\mathrm{Fo}^{\prime}\right)(\mathbf{c})$

Figure 4a shows the values of the $\mathrm{Fv}^{\prime} / \mathrm{Fm}^{\prime}\left(R^{2}=0.54\right.$, $p=0.062)$ as a function of frequency. At frequencies of 50 and $100 \mathrm{kHz}$, the $\mathrm{Fv}^{\prime} / \mathrm{Fm}^{\prime}$ was less than 0.6 and at frequencies of 0.1 and $1 \mathrm{~Hz}$ the values were 0.73 . The greater the value of $\mathrm{Fv}^{\prime} / \mathrm{Fm}^{\prime}$, the greater the maximum efficiency of the PSII photochemistry when all reaction centers are open. According to the experiment, the pulsed light frequencies that generated optimal results for $\mathrm{Fv}^{\prime} / \mathrm{Fm}^{\prime}$ were $0.1,1 \mathrm{y}$ 

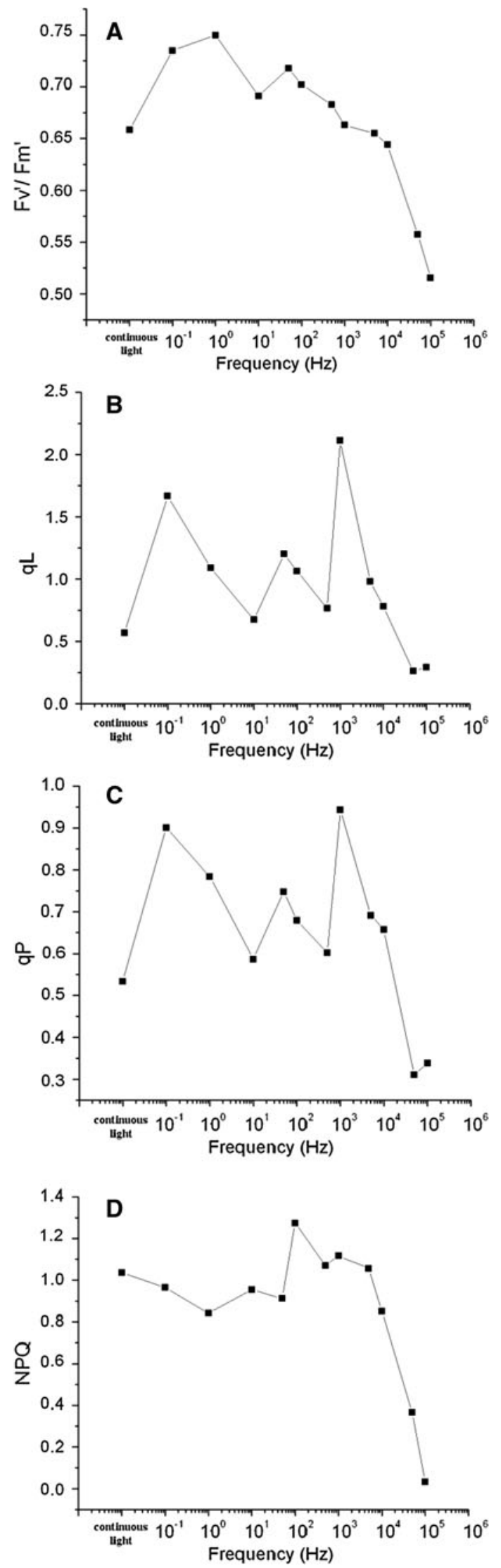

4 Fig. 4 Chlorophyll fluorescence emission yields as a function of frequency from $0.1 \mathrm{~Hz}$ down to $100 \mathrm{kHz}$ for tomato plants. Maximum efficiency of PSII from light-adapted leaf $\left(\mathrm{Fv}^{\prime} / \mathrm{Fm}^{\prime}\right)(\mathbf{a})$, fraction of PSII centers that are $\mathrm{qL}(\mathbf{b}), \mathrm{qP}(\mathbf{c})$ and NPQ (d)

$50 \mathrm{~Hz}$. Regarding the statistical analysis applied to this parameter, the maximum operational efficiency of PSII $\left(\mathrm{Fv}^{\prime} / \mathrm{Fm}^{\prime}\right)$ had a relatively high $R^{2}$, but the $p$ value was greater than 0.05 (95\% confidence intervals) which indicates there is no significant relationship between $\mathrm{Fv}^{\prime} / \mathrm{Fm}^{\prime}$ and the frequency of pulsed light. Figure $4 \mathrm{~b}$ shows the values of $\mathrm{qL}\left(R^{2}=0.69, p=0.012\right)$, for each frequency, the higher values were obtained from the treatments with $0.1 \mathrm{~Hz}$ and $1 \mathrm{kHz}(>1.5)$ and the lowest were for 50 and $100 \mathrm{kHz}(<0.5)$. For the parameter $\mathrm{qL}$, the greater the value the greater the number of open reaction centers the plant have. The $\mathrm{qL}$ had a $R^{2}$ of 0.69 with a $p$ value of 0.012 (greater than 0.05) which indicates a strong relationship between this parameter and the pulsed light frequencies. The frequencies that had the best $\mathrm{qL}$ values were $0.1 \mathrm{~Hz}$ and $1 \mathrm{kHz}$. Figure $4 \mathrm{c}$ shows the values of $\mathrm{qP}\left(R^{2}=0.59\right.$, $p=0.036)$ for each frequency. This value represents the proportion of excitation energy captured by open reaction centers and used for electronic transport of PSII (González Moreno et al. 2008). The values of the $\mathrm{qP}$ parameter were higher at frequencies of $0.1 \mathrm{~Hz}$ and $1 \mathrm{kHz}$ and lower at frequencies of 50 and $100 \mathrm{kHz}$. The greater the $\mathrm{qP}$ value, the better the use of light by the plant. The $\mathrm{qP}$ had a $p$ value of 0.036 (greater than 0.05 ) which indicates a strong relationship between $\mathrm{qP}$ and the pulsed light frequencies. The frequencies that had the best $\mathrm{qP}$ values were $0.1 \mathrm{~Hz}$ and $1 \mathrm{kHz}$. The parameter NPQ $\left(R^{2}=0.54, p=0.062\right)$ is shown in Fig. 4d. NPQ relates the influence of non-photochemical processes in the fluorescence emission. The lowest values were at frequencies of 50 and $100 \mathrm{kHz}$ below 0.4 , and the higher values corresponded to $100 \mathrm{~Hz}$ and $1 \mathrm{kHz}$ greater than 1.1. For the NPQ parameter, the lower the value, the lower the amount of energy used for nonphotochemical processes. According to the $p$ value of 0.062 and $R^{2}$ of 0.54 , there is no significant relationship between the pulsed light and this parameter.

Figure 5 shows the ФPSII $\left(R^{2}=0.86, p=0.002\right)$ values for each frequency. The frequencies at which it had the lowest values were 50 and $100 \mathrm{kHz}$ with values below 0.3 . The frequencies that had the highest values were $0.1,1,50$ and $100 \mathrm{~Hz}$ with values greater than 0.52 . This parameter is the most important in the analysis of the fluorescence emission. The ФPSII indicates the proportion of light absorbed by chlorophyll associated with Photosystem II and is used for the photochemistry of the plant. The greater the ФPSII value, the greater the quantum efficiency of Photosystem II. The statistical analysis shows that DPSII had greater significance $\left(p\right.$ value $=0.002$ ) than $\mathrm{Fm}^{\prime}, \mathrm{Fo}^{\prime}$, $\mathrm{Fs}, \mathrm{Fv}^{\prime} / \mathrm{Fm}^{\prime}$, qL, qP and NPQ parameters. The ФPSII values 


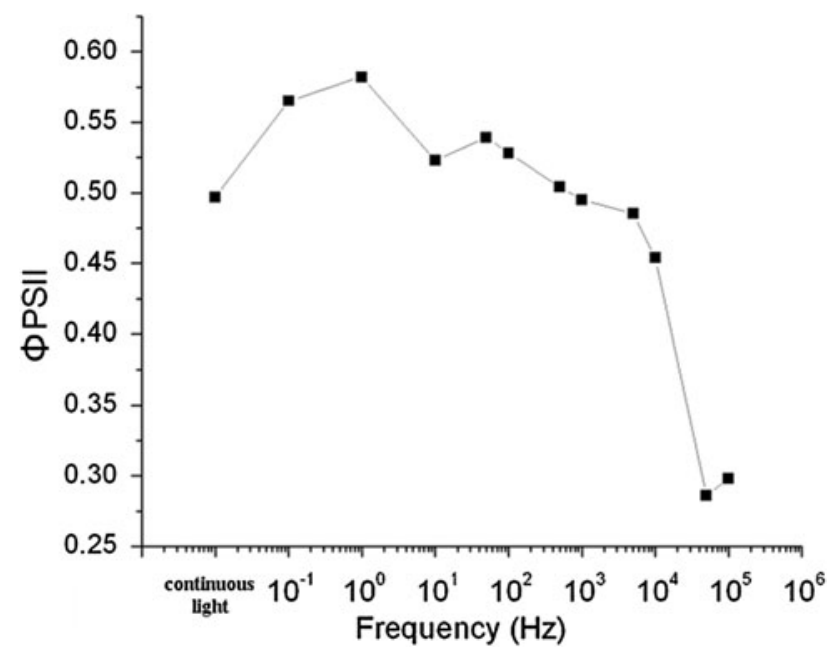

Fig. 5 Values of the parameters of ФPSII as a function of frequency from $0.1 \mathrm{~Hz}$ up to $100 \mathrm{kHz}$ for tomato plants

had a strong relationship with the pulsed light frequencies. The frequencies at which the highest values for ФPSII were measured were $0.1,1,50$ and $100 \mathrm{~Hz}$. The ETR and quantum yield of $\mathrm{CO}_{2}\left(\phi \mathrm{CO}_{2}\right)$ assimilation parameters are good indicators to determine which light treatments affect or benefit the growth of tomato plants, and are represented by linear equations directly dependent on the $\Phi$ PSII parameter (Baker 2008). This means that if the ФPSII parameter increases, the ETR and $\phi \mathrm{CO}_{2}$ parameters will have higher values.

In the analysis of multiple comparisons based on Dunn's test is shown in Table 2, significant differences between treatments (frequencies of pulsed light) for all parameters of chlorophyll fluorescence (Fs, qL, qP, ФPSII, ETR and $\phi$ $\mathrm{CO}_{2}$ ) were detected. The frequencies of pulsed light that were significantly different from $0.1,1,50$ and $100 \mathrm{~Hz}$ were 50 and $100 \mathrm{kHz}$ (Figs. 3, 4, 5).

When using the pulsed light technique it is necessary to synchronize the time of plant light exposure (light period) and the time of darkness (dark period). With this synchronization, it is possible that the plant has a better use of light (optimize the photosynthetic process). At the moment, the optimal times of light/dark periods are unknown. To complement the results shown in this paper, it is necessary to develop several experiments with pulsed light in order to measure its effects on fresh weight, dry weight and leaf area.

\section{Conclusion}

With the analysis of the fluorescence parameters of chlorophyll shown in this paper, we conclude that there exist significant effects between pulsed light frequencies and the Fs, $\mathrm{qL}, \mathrm{qP}$, ФPSII, ETR and $\phi \mathrm{CO}_{2}$ parameters. It is relevant to mention that in this article a duty cycle of $50 \%$ with $750 \mu \mathrm{mol} \mathrm{m}{ }^{-1} \mathrm{~s}^{-1}$ was applied. The amount of time during the light period and the darkness period (duty cycle) was the same in the experiment. If this cycle or the light intensity were changed, the results may be different.

Tested pulsed light frequencies produced positive and negative effects on the fluorescence parameters in comparison to the treatment of continuous light on tomato plants. The subset of frequencies $0.1,1,50,100 \mathrm{~Hz}$ and $1 \mathrm{kHz}$ had better values in $\Phi P S I I, \mathrm{Fv}^{\prime} / \mathrm{Fm}^{\prime}$ and NPQ parameters. According to our results these frequencies could be applied to artificial lighting systems to plant growth. Further research is needed in order to optimize the light absorption by the crops, to get lower power consumption and also to obtain more efficient crop growth.

Acknowledgments The authors would like to thank the FOMIX CONACyT-Gobierno del Estado de Zacatecas for the invaluable support that made possible to achieve this research. Project No. ZAC2007-CO1-82136.

Open Access This article is distributed under the terms of the Creative Commons Attribution License which permits any use, distribution, and reproduction in any medium, provided the original author(s) and the source are credited.

\section{References}

Baker NR (2008) Chlorophyll fluorescence: a probe of photosynthesis in vivo. Annu Rev Plant Biol 59:89-113

Barta DJ, Tibbits TW, Bula RJ, Morrow RC (1992) Evaluation of light emitting diode characteristics for a space-based plant irradiation source. Adv Space Res 12:141-149

Bula RJ, Morrow RC, Tibbits TW, Barta DJ (1991) Light-emitting diodes as a radiation source for plants. HortScience 26:203-205

Dougher TAO, Bugbee B (2001) Differences in the response of wheat, soybean, and lettuce to reduced radiation. Photochem Photobiol 73:199-207

Folta KM, Koss LL, McMorrow R, Kim HH, Kenitz JD, Wheeler R, Sager JC (2005) Design and fabrication of adjustable red-greenblue LED light arrays for plant research. BMC Plant Biol 5:1-11

Genty B, Briantais JM, Baker NR (1989) The relationship between the quantum yield of photosynthetic electron transport and quenching of chlorophyll fluorescence. Biochim Biophys Acta 990:87-92

Goins G, Yorio N, Sanwo M, Brown C (1997) Photomorphogenesis, photosynthesis, and seed yield of wheat plants grown under red light-emitting diodes (LEDs) with and without supplemental blue lighting. J Exp Bot 48:1407-1413

González Moreno S, Perales Vega H, Salcedo Alvarez MO (2008) La fluorescencia de la clorofila a como herramienta en la investigación de efectos tóxicos en el aparato fotosintético de plantas y algas. Rev Educ Bioquím 27:119-1129

Goto E (2003) Effects of light quality on growth of crop plants under artificial lighting. Environ Control Biol 41:121-132

Hoenecke ME, Bula RJ, Tibbits TW (1992) Importance of 'blue' photon levels for lettuce seedling grown under red-light-emitting diodes. HortScience 27:427-430

Hogewoning SW, Trouwborst G, Engbers GJ, Harbinson J, Van Ieperen W, Ruijsch J, Schapendonk AHCM, Pot SC, Van Kooten 
O (2007) Plant physiological acclimation to irradiation by lightemitting diodes (LEDs). Acta Hortic (ISHS) 761:183-191

Hu Y, Li P, Jiang J (2007) Developing a new supplemental lighting device with ultra-bright white LED for vegetables. Proc of SPIE 6486:1-9

Joiner J, Yoshida Y, Vasilkov AP, Yoshida Y, Corp LA, Middleton EM (2011) First observations of global and seasonal terrestrial chlorophyll fluorescence from space. Biogeosciences 8:637-651

Maxwell K, Johnson GN (2000) Chlorophyll fluorescence-a practical guide. J Exp Bot 51:659-668

Minitab (2003) Minitab statistical software release 14.1. Minitab, Inc

Mishra A, Mishra KB, Höermiller II, Heyer AG, Nedbal L (2011) Chlorophyll fluorescence emission as a reporter on cold tolerance in Arabidopsis thaliana accessions. Plant Signal Behav 6:301-310

Nhut DT, Nam NB (2010) Light-emitting diodes (LEDs): an artificial lighting source for biological studies. In: ICDBME in Vietnam, IFMBE Proceedings 27, pp 134-139

Okamoto K, Yanagi T, Takita S, Tanaka M, Higuchi T, Uchida Y, Watanabe H (1996) Development of plant growth apparatus using blue and red LED as artificial light source. Acta Hortic (ISHS) 440:111-116

Spalding EP, Folta KM (2005) Illuminating topics in plant photobiology. Plant, Cell Environ 28:39-53

Steinitz B, Poff KL (1986) A single positive phototropic response induced with pulsed light in hypocotyls of Arabidopsis thaliana seedlings. Planta 168:305-315

Tamulaitis G, Duchovskis P, Bliznikas Z, Breive K, Ulinskaite R, Brazaityte A, Novickovas A, Zukauskas A (2005) High-power light-emitting diode based facility for plant cultivation. J Phys D Appl Phys 38:3182-3187

Tennessen DJ, Singsaas EL, Sharkey TD (1994) Light-emitting diodes as a light source for photosynthesis research. Photosynth Res 39:85-92

Tennessen DJ, Bula RJ, Sharkey TD (1995) Efficiency of photosynthesis in continous and pulsed light emitting diode irradiation. Photosynth Res 44:261-269

Wang H, Gu M, Cui J, Shi K, Zhou Y, Yu J (2009) Effects of light quality on $\mathrm{CO}_{2}$ assimilation, chlorophyll-fluorescence quenching, expression of Calvin cycle genes and carbohydrate accumulation in Cucumis sativus. J Photochem Photobiol, B 96:30-37

Wongnok A, Piluek C, Techasilpitak T, Tantivivat S (2008) Effects of light emitting diodes on micropropagation of Phalaenopsis orchids. Acta Hortic (ISHS) 788:149-156

$\mathrm{Xu}$ ZZ, Zhou GS, Wang YL, Han GX, Li YJ (2008) Changes in chlorophyll fluorescence in maize plants with imposed rapid dehydration at different leaf ages. J Plant Growth Regul 27: 83-92

Yanagi T, Okamoto K (1997) Utilization of super-bright light emitting diodes as an artificial light source for plant growth. Acta Hortic (ISHS) 418:223-228

Yoneda K, Mori Y (2004) Method of cultivating plant and illuminator for cultivating plant. European Patent Office EP1374665A1

Yorio N, Goins G, Kagie HR, Wheeler RM, Sager JC (2001) Improving spinach, radish, and lettuce growth under red lightemitting diodes (LEDs) with blue light supplementation. HortScience 36:380-383 